\title{
COMPARATIVE EVALUATION OF THE ADAPTATION OF TWO CALCIUM SILICATE-BASED ENDODONTIC SEALERS WITH A CONVENTIONAL RESIN-BASED SEALER TO DENTINAL WALLS: AN IN VITRO SCANNING ELECTRON MICROSCOPIC STUDY
}

\author{
Heba Ahmed ElAsfouri* and Abeer Ahmed Saba**
}

\begin{abstract}
Aim of the study: The aim of this study was to compare the adaptation of two calcium silicatebased root canal sealers with a resin-based sealer to root canal walls at the middle and apical levels using scanning electron microscope.

Material and methods: Twenty-six single-canalled lower premolars were instrumented and randomly divided into three groups according to the sealer used with gutta-percha ( $n=8)$; AH plus, Bioroot RCS, and Endoseal MTA. Two random specimens served as the blank control group to assess the smear layer removal from the dentinal walls. Teeth were sectioned at middle and apical levels and gap width was evaluated using scanning electron microscope. Data were statistically analyzed with significance level set at $p \leq 0.05$.
\end{abstract}

Results: At the apical and mid-root levels, the highest mean values were found in Endoseal MTA group followed by Bioroot RCS group while the lowest mean value was found in AH Plus group with statistically significant difference between all groups. Statistically significant differences were found between Endoseal MTA and each of Bioroot RCS and AH Plus groups. No statistically significant difference was found between Bioroot RCS and AH Plus groups.

Conclusions: AH Plus and Bioroot RCS showed statistically better results than Endoseal MTA regarding adaptation to the root canal walls.

KEYWORDS: AH Plus, Bioroot RCS, Endoseal MTA, Adaptation, Scanning Electron Microscope.

* Lecturer of Endodontics, Faculty of Dentistry, Cairo University.

** Associate Professor of Endodontics, Faculty of Dentistry, Cairo University. 


\section{INTRODUCTION}

Poorly filled spaces in root canals could be the cause of bacterial growth. It was reported that $58 \%$ of root canal treatment failures were due to incomplete obturation ${ }^{1}$. Thereby, a three-dimensional canal space filling with a biocompatible material is the ultimate goal to avoid bacterial leakage. Since gutta-percha, as a core filling material, does not directly bond to the canal walls, a root canal sealer is mandatory. Endodontic sealers ensure sealing the canal system by filling the anatomical irregularities, ramifications and dentinal tubules, hence enhancing the adaptation of root filling at the dentin material interface $^{2}$. The ability of root canal sealers to adhere to the core material and to the dentin, adds an advantage in sealing ability and reduction of leakage ${ }^{3}$.

Epoxy resin-based root canal sealer AH Plus (Dentsply, Germany) has been used as the gold standard for comparison with other sealers. It offers the advantages of reduced solubility, microretention to the root dentin and tight apical seal. Its toxicity when freshly mixed and inability to bond to gutta-percha however remain problems ${ }^{4}$.

In the continuous attempt to improve the performance of root canal sealers, new calcium silicate-based sealers have been developed. Bioroot RCS (Septodont, Louisville, USA), is a waterbased bioceramic sealer that showed excellent biocompatibility in fresh and set states ${ }^{5}$. It is supplied in powder and liquid form; the powder is compsed of tricalcium silicate, povidone and zirconium oxide; the liquid is an aqueous solution of of calcium chloride and polycarboxylate. When contacting the physiologic solution, this sealer releases calcium and forms an interfacial calcium phosphate (apatite) layer, developing a chemical bond with the dentinal walls and presumes to enhance its adaptability ${ }^{6,7}$.

Endoseal MTA (Maruchi, Wonju, South Korea), is another calcium silicate-MTA-based endodontic sealer, containing calcium silicates, calcium aluminates, calcium aluminoferrite, and calcium sulfates. It is a paste-type, premixed root canal sealer based on pozzolan cement that has superior physical and biological properties of MTA. It is preloaded in a syringe allowing its direct application into the root canal. According to the manufacturer, its advantages include; fast setting time, antibacterial effect, biocompatibility, adequate flow, excellent film thickness, and also hard tissue formation stimulation $^{8}$.

Good adaptation between sealer and root canal wall not only decreases the chance of microleakage, but also increases the fracture strength of the $\operatorname{root}^{9,10,11}$. Adaptation of sealers to canal walls and marginal gaps can be evaluated with scanning electron microscope (SEM), observing the defects at submicron level at the required magnification ${ }^{12}$.

To our knowledge, few studies have assessed the adaptation of the sealers used in this study. Therefore, the current study was adopted to compare the adaptation of three sealers; AH Plus, Bioroot RCS and Endoseal MTA. The null hypothesis was that there is no significant difference between the three sealers in their adaptation to root canal walls.

\section{MATERIALS AND METHODS}

\section{Specimen Preparation}

Twenty-six freshly extracted human singlerooted mandibular premolar teeth without caries, apical or surface resorption and cracks were selected. Teeth with curved roots, abnormal canal morphology and having pulpal calcifications were excluded from the study. To preserve the humidity of dentinal tubules, teeth were stored in saline solution till the time of use.

Teeth were decoronated to standardize the length of the root canal at $14 \mathrm{~mm}$. The working length was determined by inserting a size $10 \mathrm{~K}$-file (Dentsply Maillefer, Ballaigues, Switzerland) into the canal until the file was just visible at the apical foramen and then subtracting $1 \mathrm{~mm}$. The root canals were 
instrumented using ProTaper rotary files (Dentsply Maillefer) up to size F3. Canals were irrigated with $3 \mathrm{~mL}$ of $5.25 \%$ sodium hypochlorite $(\mathrm{NaOCl})$ between instruments. After complete preparation, smear layer was removed using $5 \mathrm{~mL}$ of $17 \%$ ethylenediaminetetraacetic acid (EDTA) solution, $5 \mathrm{~mL}$ of $5.25 \% \mathrm{NaOCl}$ and finally flushed with $10 \mathrm{~mL}$ distilled water. The specimens were dried using sterile absorbent paper points (Dentsply, Maillefer).

Two random specimens were selected to serve as blank control group to assess the smear layer removal from the dentinal walls. The remaining 24 samples were randomly and equally divided into 3 groups $(\mathrm{n}=8)$ according to the type of sealer used: group I: AH Plus, group II: Bioroot RCS and group III: Endoseal MTA.

In $\mathrm{AH}$ Plus and BioRoot RCS groups, the sealers were prepared according to manufacturer's instructions and introduced into the canal with size \#25 Lentulospiral (Dentsply, Maillefer, Ballaigues, Switzerland) at 300 rotations/min to the working length until complete filling of the canal. In Endoseal MTA group, the sealer was injected into the root canal using intracanal tip supplied by the manufacturer, to fill the apical part then slowly withdrawn while sealer was injected until complete filling of the canal.

For the three experimental groups, lateral condensation technique was employed for root canal obturation with master cone size 30/0.06 and completed with size 25/0.02 auxiliaries. The coronal access of all groups was sealed with temporary filling material and the samples were stored in $100 \%$ humidity at $37^{\circ} \mathrm{C}$ for 10 days to allow the sealers to set.

\section{Assessment of adaptation}

After the storage period, the roots were embedded into acrylic resin vertically and sectioned horizontally with Isomet precision cutting machine (Buehler, Germany) at 3, and $7 \mathrm{~mm}$ from the apex representing the apical and middle thirds, respectively. Specimens of the control group were further cut vertically for assessment of smear layer removal. Sections were then washed with distilled water for $5 \mathrm{~min}$ and dehydrated for observation by scanning electron microscope (SEM). The samples were mounted on an aluminum stub and viewed under SEM (Quanta 250 FEG (Field Emission Gun) attached with EDX Unit (Energy Dispersive X-ray Analyses) (FEI company, Netherlands), with accelerating voltage $30 \mathrm{KV}$. Interfacial gaps between the sealer and root dentin interface were evaluated under $\times 2000$ magnification at middle and apical halves of the root canal by taking photomicrographs. For each section, the maximum gap in microns $(\mu \mathrm{m})$ was recorded.

\section{Statistical analysis}

The mean and standard deviation values were calculated for each group. Data were explored for normality using Kolmogorov-Smirnov and ShapiroWilk tests, data showed parametric (normal) distribution. Paired wise sample t-test was used to compare between two groups in related samples. One-way ANOVA followed by Tukey post hoc test was used to compare between more than two groups in non-related samples. Two-way ANOVA was used to test the interaction between different variables. The significance level was set at $p \leq 0.05$. Statistical analysis was performed with IBM® ${ }^{\circledR}$ SPSS ${ }^{\circledR}$ Statistics Version 20 for Windows.

\section{RESULTS}

The control group showed open dentinal tubules, despite some remaining debris, which did not occlude the tubules Figure (1).

The results were summarized in Table (1) and Figure (2). AH Plus showed the least gap width at middle and apical levels figure (3A), followed by Bioroot RCS figure (3B), the Endoseal MTA figure (3C), which showed the highest mean gap width. In all groups the mean gap width was higher at middle than at the apical third. 
At the apical level, a statistically significant difference was found between Bioroot RCS, AH Plus and Endoseal MTA groups where $(p<0.001)$. A statistically significant difference was also found between Endoseal MTA group and each of Bioroot RCS and AH Plus groups where $(\mathrm{p}<0.001)$. However, no statistically significant difference was found between Bioroot RCS and AH Plus groups where $(\mathrm{p}=0.502)$.

At the middle level, a statistically significant difference was found between Bioroot RCS, AH Plus and Endoseal MTA groups where $(p<0.001)$. A statistically significant difference was also found between Endoseal MTA group and each of Bioroot RCS and AH Plus groups where $(p<0.001)$. On the other hand, no statistically significant difference was found between Bioroot RCS and AH Plus where $(\mathrm{p}=0.986)$.

In $\mathrm{AH}$ Plus group, a statistically significant difference was found between (Apical $/ 3 \mathrm{~mm}$ ) and (Middle $/ 7 \mathrm{~mm})$ where $(p=0.002)$. The highest mean value was found in (Middle/7mm) while the lowest mean value was found in (Apical/3mm).

While in Bioroot RCS group, no statistically significant difference was found between (Apical $/ 3 \mathrm{~mm}$ ) and (Middle $/ 7 \mathrm{~mm})$ where $(p=0.056)$, although the highest mean value was found in (Middle $/ 7 \mathrm{~mm}$ ) and the lowest mean value was found in (Apical/3mm).

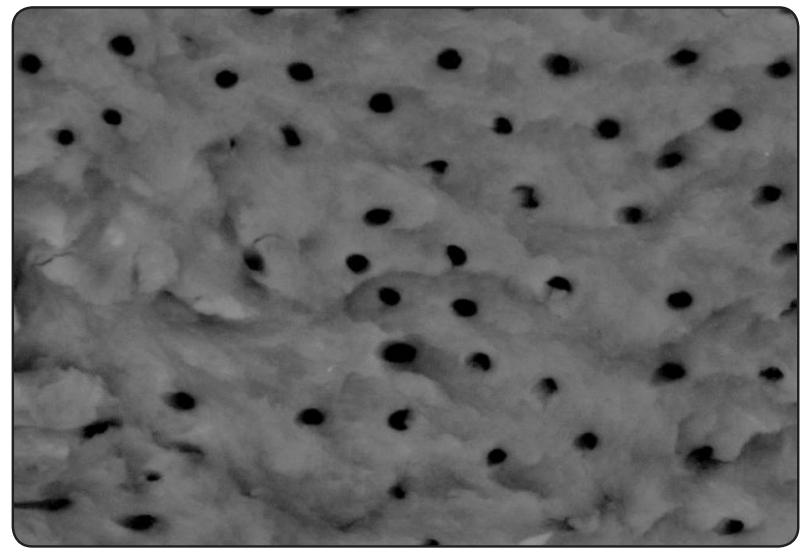

Fig. (1): SEM showing opened dentinal tubules of the control group

As for the Endoseal MTA group, a statistically significant difference was found between (Apical $/ 3 \mathrm{~mm}$ ) and (Middle $/ 7 \mathrm{~mm})$ where $(p=0.001)$, the highest mean value was found in (Middle/7mm) and the lowest mean value was found in (Apical/3mm).

Data in Table (2) shows the results of Two-way ANOVA analysis for the interaction of different variables. The results showed that different sealers had a statistically significant effect at $p$-value $<0.001$. Also, root level had a statistically significant effect at $p$-value $<0.001$. The interaction between the two variables had a statistically significant effect at $p$-value $=0.005$.

TABLE (1): The mean and standard deviation (SD) of gap width in different thirds of different groups.

\begin{tabular}{|c|c|c|c|c|c|c|c|}
\hline \multirow{3}{*}{ Variables } & \multicolumn{7}{|c|}{ Gap width } \\
\hline & \multicolumn{2}{|c|}{ Bioroot RCS } & \multicolumn{2}{|c|}{ AH Plus } & \multicolumn{2}{|c|}{ Endoseal MTA } & \multirow[t]{2}{*}{ p-value } \\
\hline & Mean & SD & Mean & SD & Mean & SD & \\
\hline Apical/ 3mm & $3.25^{\mathrm{aB}}$ & 2.05 & вв 2.47 & 0.80 & $7.55^{\mathrm{bA}}$ & 0.84 & $<0.001 *$ \\
\hline Middle/ $7 \mathrm{~mm}$ & $5.02^{\mathrm{aB}}$ & 3.04 & aB 4.80 & 1.58 & $14.17^{\mathrm{aA}}$ & 3.31 & $<0.001 *$ \\
\hline p-value & \multicolumn{2}{|c|}{$0.056 \mathrm{~ns}$} & \multicolumn{2}{|c|}{$0.002 *$} & \multicolumn{2}{|c|}{$0.001 *$} & \\
\hline
\end{tabular}

Means with different small letters in the same column indicate statistically significant difference; means with different capital letters in the same row indicate statistically significant difference. *; significant $(p<0.05) \quad$ ns; non-significant (p>0.05) 


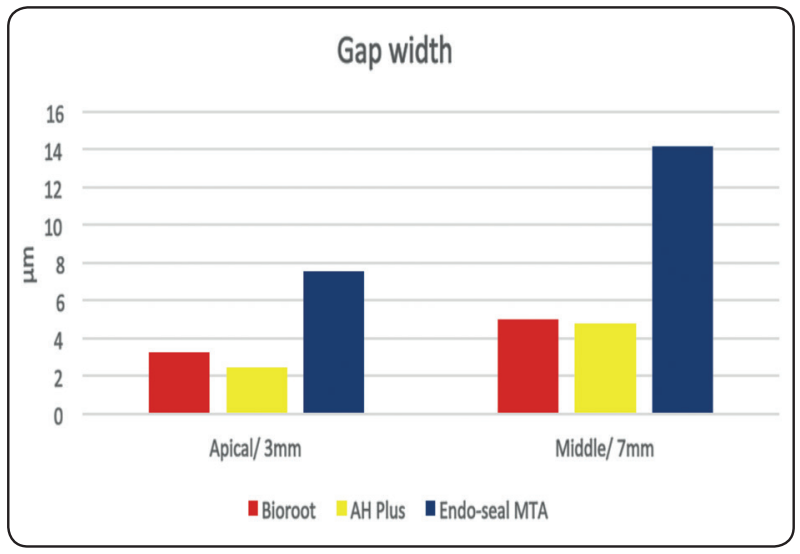

Fig. (2): Bar chart representing gap width of different groups
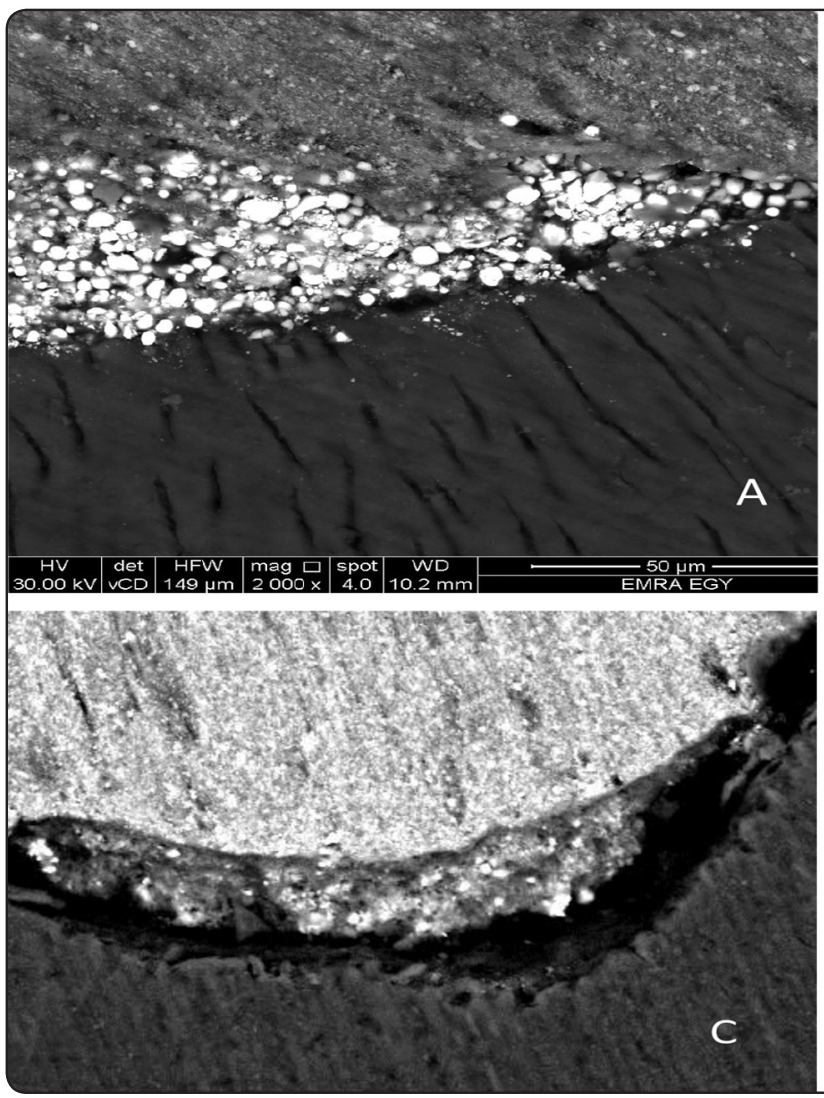

\section{DISCUSSION}

At the apical and middle root levels, a statistically significant difference was found between AH Plus, BioRoot RCS and Endoseal MTA groups $(p<0.001)$. Based on these results, the null hypothesis was rejected in this study.
TABLE (2): Results of Two-way ANOVA for the effect of different variables on gap distance evaluation.

\begin{tabular}{|c|c|c|c|c|c|}
\hline & Type III & df & $\begin{array}{c}\text { Mean } \\
\text { Square }\end{array}$ & $\begin{array}{c}F- \\
\text { value }\end{array}$ & $\begin{array}{c}P- \\
\text { value }\end{array}$ \\
\hline Sealers & 520.796 & 2 & 260.398 & 55.343 & $<.001^{*}$ \\
\hline Root level & 153.117 & 1 & 153.117 & 32.542 & $<.001^{*}$ \\
\hline $\begin{array}{c}\text { Sealers x root } \\
\text { level interaction }\end{array}$ & 56.073 & 2 & 28.036 & 5.959 & $.005^{*}$ \\
\hline
\end{tabular}

$d f:$ degrees of freedom $=(n-1), *$ Significant at $P \leq 0.05$

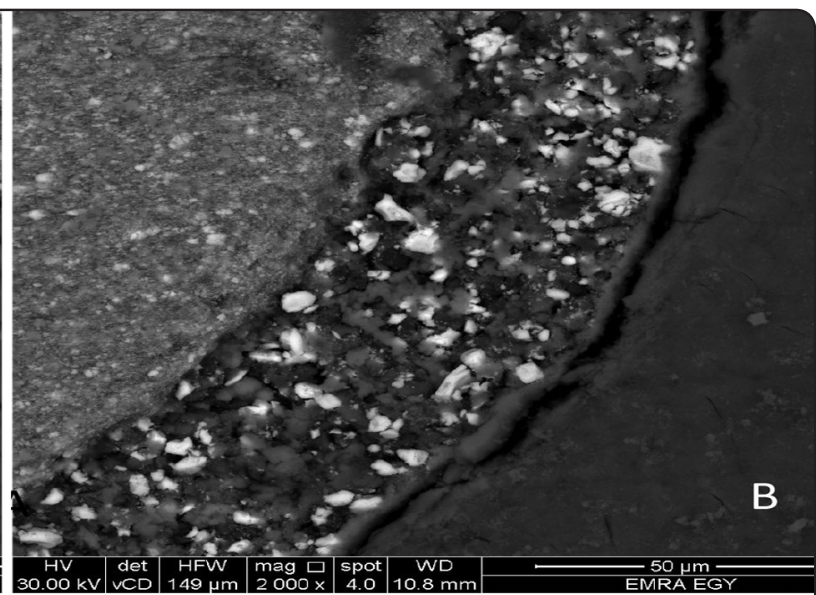

Fig. (3) Scanning electron microscope images x2000 of gap width between dentin walls and AH Plus (A), and Bioroot RCS (B), and Endoseal MTA (C)
The main function of a root canal sealer is to fill the imperfections and increase the adaptation of the filling material to the root canal walls. Ideal root canal sealer must be biocompatible, and should have low surface tension to allow penetration into irregularities and good wettability to provide fluid tight seal..$^{13}$ 
In this study, scanning electron microscope was used for the assessment of marginal gap along with horizontal cross-sectioning of the specimens. This allowed observing the adaptation and measuring the defects around the entire canal lumen at the selected levels for a more precise and complete evaluation, unlike vertical sectioning of specimens which permits evaluation in only two selected planes.

The lateral condensation of gutta-percha with the root canal sealers was chosen to be the obturation method in this study. Since the sealer may display a variable level of solubility, depending on its physical and chemical nature, it is crucial to utilize a sealer that has a minimum film thickness adjacent to the dentinal wall ${ }^{14,15}$. Moreover, by revealing a thin film thickness, the sealer may also infiltrate deeper into the canal irregularities. Hence, the supreme outcome of root canal obturation is to achieve a great volume of gutta-percha and a least volume of sealer within the root canal space ${ }^{12,16}$ with improved permeation into the canal irregularities and dentinal tubules.

Degree of adhesion and penetration of sealers into dentinal tubules is influenced by several factors such as physical and chemical properties of the sealers, dentin permeability, filling technique, and smear layer removal ${ }^{17}$. The significance of smear layer removal was assessed by Oksan et al. $1993^{18}$, Kouvas et al.1998 ${ }^{19}$, Kokkas et al $.2004^{20}$, and Sonu et al. $2016^{21}$, who concluded that the removal of smear layer had lead to the deeper penetration of sealers into dentinal tubules, thus reducing microleakage and increasing the root canal treatment success rate.

The use of a chelating agent such as 17\% EDTA solution to remove the inorganic component, followed by $5.25 \% \mathrm{NaOCl}$ solution to dissolve any remaining organic component is the most commonly used regimen to remove the smear layer ${ }^{22,23,24}$. EDTA easily enters dentinal tubules due to its low surface tension and eliminates smear layer up to the depth of 2.5-4 $\mu \mathrm{m}^{25}$. Thus bonding and adaptation of sealers to root canal walls are expected to increase ${ }^{26}$.
Finally, distilled water was used to counteract the lasting effect of irrigants used.

In contrast with the results of previous studies ${ }^{27,28}$, in this study less gap width was observed at apical level for all the sealers than at middle level. This difference could be accounted to the round cross section at the apical region conforming more to the round cross section of the filling core material. Greater mean gaps at the middle root area could be ascribed to the difficulty posed by the premolar root canals' oval shape. Published literature had indicated that this area could prove challenging during preparation and subsequent filling, especially with cold lateral compaction ${ }^{29}$ hence might affect the sealer diffusion into the root dentin ${ }^{30}$.

AH Plus sealer exhibited the least gap width values with the root dentin, a result which came in agreement with many previous studies ${ }^{31,32,33}$. AH Plus enhanced interfacial bonding and adaptation could be attributed to many factors. Its chemical bonding to root dentin by forming covalent bonds between the epoxy resin and any exposed amino groups in collagen might be one of the causes of the excellent adaptation. Besides, being chemically cured, AH Plus compensates for polymerization shrinkage and exhibits zero polymerization stresses ${ }^{34,35}$. AH Plus also shows pseudoplastic behavior, a term describing liquids exhibiting a thixotropic behavior by a decrease in viscosity when there is an increase in shear rate during compaction ${ }^{36}$. Furthermore, the slight acidity of AH Plus might result in selfetching when comes in contact with dentin, thereby enhancing bonding and adaptation ${ }^{17}$.

In our study, BioRoot RCS showed similar adaptation to dentinal walls as AH Plus. It has been shown that infiltration of BioRoot RCS mineral content into the intertubular dentin, results in the formation of a mineral infiltration zone after denaturation of the collagen fibers by the strong alkalinity of the sealer ${ }^{37,38}$

Moreover, previous studies demonstrated that BioRoot RCS had higher calcium ion release 
over a prolonged duration than other sealers. This prolonged mineralizing ion release triggers the nucleation of calcium phosphate resulting in the formation of hydroxyapatite along the mineral infilteration zone which may improve the adaptation and sealing of the sealer ${ }^{39,40,41}$.

Although Endoseal MTA has also demonstrated an alkaline nature and calcium release, yet in this study it showed more interfacial gaps and the least adaptation to dentinal walls. Previous studies suggested that the reason of the low bonding efficiency of MTA-based sealers to dentinal tubules was due to the formation of apatite by MTA over its own surface, hence creating poor microtags on setting ${ }^{42,43}$.

Another possible explanation could be as described by Türker et $\mathrm{al}^{44}$, who evaluated the effect of smear layer removal on the adhesion of MTA-based sealer with root canal dentin, and concluded that the smear layer had an essential role in the formation of the interfacial layer between the MTA-based sealers and root dentin. Yildirim et al ${ }^{45}$ reported that due to the humidity of the root canal wall, the smear layer, which acts a coupling agent, might have a helpful effect on the adhesion of MTAbased sealers to the root canal dentin.

Since not used in bulk, the MTA-based sealers in the middle part of root might remain unset due to lack of water for hydration reaction unlike the apical part of the root, which might be the cause of increased interfacial gaps in the middle root sections ${ }^{46}$.

\section{CONCLUSIONS}

Within the limitations of this study it could be concluded that AH Plus and BioRoot RCS were better than Endoseal MTA regarding adaptation to the root canal walls. Although MTA has confirmed to be successful in numerous other clinical applications, further researches should be conducted to decide whether MTA-based sealers themselves or the method of their placement could be adjusted to enhance their performance as a root canal sealers.

\section{REFERENCES}

1. Silva RV, Silveira FF, Horta MC, Duarte MA, Cavenago BC, Morais IG, Nunes E. Filling effectiveness and dentinal penetration of endodontic sealers: a stereo and confocal laser scanning microscopy study. Brazilian dental journal. 2015 Oct;26(5):541-6.

2. Mohammadian F, Farahanimastary F, Dibaji F, Kharazifard MJ. Scanning electron microscopic evaluation of the sealer-dentine interface of three sealers. Iranian endodontic journal. 2017;12(1):38

3. Saleh IM, Ruyter IE, Haapasalo MP, Ørstavik D. Adhesion of endodontic sealers: scanning electron microscopy and energy dispersive spectroscopy. Journal of endodontics. 2003 Sep 1;29(9):595-601.

4. Resende LM, Rached-Junior FJ, Versiani MA, SouzaGabriel AE, Miranda CE, Silva-Sousa YT, Sousa Neto MD. A comparative study of physicochemical properties of AH Plus, Epiphany, and Epiphany SE root canal sealers. International Endodontic Journal. 2009 Sep;42(9):785-93.

5. Jung S, Sielker S, Hanisch MR, Libricht V, Schäfer E, Dammaschke T. Cytotoxic effects of four different root canal sealers on human osteoblasts. PloS one. 2018 Mar 26;13(3):e0194467.

6. Camilleri J. Sealers and warm gutta-percha obturation techniques. Journal of endodontics. 2015 Jan 1;41(1):72-8.

7. Xuereb M, Vella P, Damidot D, Sammut CV, Camilleri J. In Situ Assessment of the Setting of Tricalcium Silicatebased Sealers Using a Dentin Pressure Model. Journal of endodontics. 2015 Jan 1;41(1):111-24.

8. Upadhyay ST, Purayil TP, Ginjupalli K. Comparative evaluation of fracture resistance of endodontically treated teeth obturated with pozzolan-based MTA sealer and epoxy resin-based sealer: an in vitro study. World Journal of Dentistry. 2017 Jan 1;8(1):37-40.

9. Marciano MA, Guimarães BM, Ordinola-Zapata R, Bramante CM, Cavenago BC, Garcia RB, Bernardineli N, Andrade FB, Moraes IG, Duarte MA. Physical properties and interfacial adaptation of three epoxy resin-based sealers. Journal of endodontics. 2011 Oct 1;37(10): 1417-21.

10. Kim YK, Grandini S, Ames JM, Gu LS, Kim SK, Pashley DH, Gutmann JL, Tay FR. Critical review on methacrylate resin-based root canal sealers. Journal of Endodontics. 2010 Mar 1;36(3):383-99. 
11. Gesi A, Raffaelli O, Goracci C, Pashley DH, Tay FR, Ferrari M. Interfacial strength of Resilon and gutta-percha to intraradicular dentin. Journal of endodontics. 2005 Nov 1;31(11):809-13.

12. Vitti RP, Prati C, Silva EJ, Sinhoreti MA, Zanchi CH, e Silva MG, Ogliari FA, Piva E, Gandolfi MG. Physical properties of MTA Fillapex sealer. Journal of endodontics. 2013 Jul 1;39(7):915-8.

13. Muliyar S, Shameem KA, Thankachan RP, Francis PG, Jayapalan CS, Hafiz KA. Microleakage in endodontics. Journal of international oral health: JIOH. 2014 Nov;6(6):99.

14. Peters DD. Two-year in vitro solubility evaluation of four gutta-percha sealer obturation techniques. Journal of Endodontics. 1986 Jan 1;12(4):139-45.

15. De-Deus G, Coutinho-Filho T, Reis C, Murad C, Paciornik S. Polymicrobial leakage of four root canal sealers at two different thicknesses. Journal of endodontics. 2006 Oct 1;32(10):998-1001.

16. Wu MK, Wesselink PR, Boersma J. A 1-year follow-up study on leakage of four root canal sealers at different thicknesses. International Endodontic Journal. 1995 Jul;28(4):185-9.

17. Al-Haddad A, KASIM NH, Ab Aziz ZA. Interfacial adaptation and thickness of bioceramic-based root canal sealers. Dental materials journal. 2015 Jul 30;34(4):51621.

18. Okşan T, Aktener BO, Şen BH, Tezel H. The penetration of root canal sealers into dentinai tubules. A scanning electron microscopic study. International Endodontic Journal. 1993 Sep;26(5):301-5.

19. Kouvas V, Liolios E, Vassiliadis I, Parissis Messimeris $\mathrm{S}$, Boutsioukis A. Influence of smear layer on depth of penetration of three endodontic sealers: an SEM study. Dental Traumatology. 1998 Aug;14(4):191-5.

20. Kokkas AB, Boutsioukis AC, Vassiliadis LP, Stavrianos $\mathrm{CK}$. The influence of the smear layer on dentinal tubule penetration depth by three different root canal sealers: an in vitro study. Journal of endodontics. 2004 Feb 1;30(2):100-2.

21. Sonu KR, Girish TN, Ponnappa KC, Kishan KV, Thameem PK. "Comparative evaluation of dentinal penetration of three different endodontic sealers with and without smear layer removal"-Scanning electron microscopic study. Saudi Endodontic Journal. 2016 Jan 1;6(1):16.
22. Jaju S, Jaju PP. Newer root canal irrigants in horizon: a review. International journal of dentistry. 2011;2011.

23. Dua A, Dua D, Uppin VM. Evaluation of the effect of duration of application of Smear Clear in removing intracanal smear layer: SEM study. Saudi Endodontic Journal. 2015 Jan 1;5(1):26.

24. Garberoglio R, Becce C. Smear layer removal by root canal irrigants: a comparative scanning electron microscopic study. Oral Surgery, Oral Medicine, Oral Pathology. 1994 Sep 1;78(3):359-67.

25. Y1lmaz Z, Basbag B, Buzoglu HD, Gümüsderelioglu M. Effect of low-surface-tension EDTA solutions on the wettability of root canal dentin. Oral Surgery, Oral Medicine, Oral Pathology, Oral Radiology, and Endodontology. 2011 Jan 1;111(1):109-14.

26. Swaty Jhamb VN, Singh V. Effect of sealers on fracture resistance of endodontically treated teeth with and without smear layer removal: An in vitro study. Journal of conservative dentistry: JCD. 2009 Jul;12(3):114.

27. Gharib SR, Tordik PA, Imamura GM, Baginski TA, Goodell GG. A confocal laser scanning microscope investigation of the epiphany obturation system. Journal of Endodontics. 2007 Aug 1;33(8):957-61.

28. Akcay M, Arslan H, Durmus N, Mese M, Capar ID. Dentinal tubule penetration of AH Plus, iRoot SP, MTA fillapex, and guttaflow bioseal root canal sealers after different final irrigation procedures: A confocal microscopic study. Lasers in surgery and medicine. 2016 Jan;48(1):70-6.

29. Wu MK, Kašt'áková A, Wesselink PR. Quality of cold and warm gutta percha fillings in oval canals in mandibular premolars. International Endodontic Journal. 2001 Sep;34(6):485-91.

30. Ng YL, Mann V, Rahbaran S, Lewsey J, Gulabivala K. Outcome of primary root canal treatment: Systematic review of the literature - Part 2.Influence of clinical factors. International Endodontic Journal. 2008;41:6-31.

31. De Deus G, Brandao MC, Leal F, Reis C, Souza EM, Luna AS, Paciornik S, Fidel S. Lack of correlation between sealer penetration into dentinal tubules and sealability in nonbonded root fillings. International endodontic journal. 2012 Jul;45(7):642-51.

32. Chen H, Zhao X, Qiu Y, Xu D, Cui L, Wu B. The tubular penetration depth and adaption of four sealers: a scanning 
electron microscopic study. BioMed research international. $2017 ; 2017$.

33. Ajwani PU, Saini NA. The influence of the smear layer on dentinal tubule penetration depth by different root canal sealers - an in vitro SEM study. Endodontology. 2010;22(2):19-26.

34. Bouillaguet S, Bertossa B, Krejci I, Wataha JC, Tay FR, Pashley DH. Alternative adhesive strategies to optimize bonding to radicular dentin. Journal of Endodontics. 2007 Oct 1;33(10):1227-30.

35. Iqbal MK, Sijiny R, Al-Zaidan H. A comparison of sealing ability of four sealer cements in apically perforated root canals. Saudi Endodontic Journal. 2011 Jan 1;1(1):12-8.

36. Zhou HM, Shen Y, Zheng W, Li L, Zheng YF, Haapasalo M. Physical properties of 5 root canal sealers. Journal of endodontics. 2013 Oct 1;39(10):1281-6.

37. Han L, Okiji T. Uptake of calcium and silicon released from calcium silicate-based endodontic materials into root canal dentine. International endodontic journal. 2011 Dec;44(12):1081-7.

38. Al-Haddad A, Ab Aziz C, Zeti A. Bioceramic-based root canal sealers: a review. International journal of biomaterials. 2016;2016.

39. Siboni F, Taddei P, Zamparini F, Prati C, Gandolfi MG. Properties of BioRoot RCS, a tricalcium silicate endodontic sealer modified with povidone and polycarboxylate. International endodontic journal. 2017 Dec;50:e120-36.

40. Xuereb M, Vella P, Damidot D, Sammut CV, Camilleri J. In situ assessment of the setting of tricalcium silicate- based sealers using a dentin pressure model. Journal of endodontics. 2015 Jan 1;41(1):111-24.

41. Prüllage RK, Urban K, Schäfer E, Dammaschke T. Material properties of a tricalcium silicate-containing, a mineral trioxide aggregate-containing, and an epoxy resin-based root canal sealer. Journal of endodontics. 2016 Dec 1;42(12):1784-8.

42. Torabinejad M, Hong CU, McDonald F, Ford TP. Physical and chemical properties of a new root-end filling material. Journal of endodontics. $1995 \mathrm{Jul}$ 1;21(7):349-53.

43. Sagsen B, Ustün Y, Demirbuga S, Pala K. Push-out bond strength of two new calcium silicate-based endodontic sealers to root canal dentine. International endodontic journal. 2011 Dec 1;44(12):1088-91.

44. Türker SA, Uzunoğlu E, Purali N. Evaluation of dentinal tubule penetration depth and push-out bond strength of AH 26, BioRoot RCS, and MTA Plus root canal sealers in presence or absence of smear layer. Journal of dental research, dental clinics, dental prospects. 2018;12(4):294.

45. Yildirim T, Er K, Taşdemir T, Tahan E, Buruk K, Serper A. Effect of smear layer and root-end cavity thickness on apical sealing ability of MTA as a root-end filling material: a bacterial leakage study. Oral Surgery, Oral Medicine, Oral Pathology, Oral Radiology, and Endodontology. 2010 Jan 1;109(1):e67-72.

46. Vizgirda PJ, Liewehr FR, Patton WR, McPherson JC, Buxton TB. A comparison of laterally condensed guttapercha, thermoplasticized gutta-percha, and mineral trioxide aggregate as root canal filling materials. Journal of endodontics. 2004 Feb 1;30(2):103-6. 